\title{
Igniting the Spark: How to Achieve Collective Ownership of a Tribal Language Revitaisation Strategy
}

\author{
(Dedicated to the memory of Uncle Jacko - Jack Tupai \\ Reihana)
}

The Kāi Tahu tribal language Strategy, Kotahi Mano Kāika, Kotahi Mano Wawata - A thousand homes, a thousand dreams, is now in its twelfth year and has recently been internally reviewed. We are the fourth largest tribe in New Zealand with over 50,000 tribal members and have the biggest tribal territory of any tribe. Yet we remain in the position of a people whose language is in the worse state of all tribes in New Zealand and we are far from achieving a level of sustainability in our efforts.

The greatest challenge we have faced and continue to face, is the engagement of the majority of our kin who are nonlanguage speakers in our revitalisation effort, and this includes a significant proportion of our tribal governance. As the language continues to take second place to the wider social and political issues facing the tribal collective, the task of revitalisation becomes increasingly challenging and desperate.

This paper will discuss the strategies that have been used over the past 12 years to achieve collective ownership of our language revitailstion effort and will look the challenges ahead of us as a tribe and as language communities to achieve language sustainability for our people and future generations.

In identifying the challenges, I would like to look at two main areas; firstly the wider challenge of achieving collective ownership of our tribal language revitaisation strategy and efforts, and secondly, consistent with our panel's theme of language transformation - Whakakau he reo: how changes in 
language acquisition trends and language transformation has an impact on those same revitalisation efforts.

So let me first start by painting the picture of the challenges we face in attempting to ignite the spark of language acquisition and understanding of the plight of our language, within my own people, the Kāi Tahu of the South Island of New Zealand. To do this I will draw on two immediate examples.

On the $4^{\text {th }}$ of November 2010, my home town of Christchurch in the South Island of New Zealand was shook from its foundations by a 7.2magnitude earthquake. This was followed on February the $22^{\text {nd }} 2011$ by a quake of 6.3magnitude that was far more devastating in terms of damage and loss of life.

Our worlds and those of our whānau or families were changed forever. The earth continued to move at regular intervals, and still does now over a year and a half after that first event. We no longer expect the certainty of water or electricity or sewage systems. We are use to driving on roads historically representative of outback towns, and we continue to live with a high level of anxiety, never knowing when the next shake is going to hit.

The earthquakes themselves would constitute enough of a reason for distress and concern, but for me it was a matter of hours after that first huge earthquake before another level of sorrow and concern hit me, and that was about our language. That might seem like an odd focus of concern for someone in the middle of a natural disaster, but on another level, perhaps not so difficult when one considers the effects that the manmade disaster - that of our tribal language death - had had on me as an individual and my family and tribe for five generations.

Allow me briefly to present the context; for nearly twenty years I had been working amongst my people in the area of language revitalisation as a teacher in academic institutions, on our local marae or long-houses or traditional villages, around the island, and within our tribal organisation. I had been an active teacher, advocate and lobbyist, driving our tribal language strategy, and had for the last 8 years had exhausted all energies in raising my two children in te reo Māori and our tribal dialect, as a second language speaker myself.

Although we had achieved many milestones over the years and now have a small but prized group of about forty young 
children who are being raised with Māori as their first and dominant language, the rate of language acquisition by our people and the level of engagement in the revitalisation effort remains pitiful and nowhere near the milestones that would have needed to be achieved to give us a sense of security about our language's future survival.

And then the ground shook. After fighting for so long to encourage our people to adopt the language and understand the urgency of language acquisition as a personal goal and as a tribal collective, and to put aside the usual excuses of; "I don't have enough time, its too hard", or "I'll start to learn it when I get a bit a spare time", and instead to prioritise the language or risk watching it die - the earth shook.

I knew at that moment, that the demands of ensuring the whānau's survival were inevitably going to take precedence and priority - yet again. I knew that issues of water, sanitation, food and shelter would dominate the lives of our community, not for just a year, but for decades to come. And I knew that the survival of our reo, of our unique South Island dialect - didn't have decades, that we didn't have years that we could afford to wait.

During the aftermath of our earthquakes, I quietly lamented the passing of our language, and questioned the strength of myself and those of my peers and relations, as to whether or not we would be able to maintain the energy required to change the ebbing tide of language loss amongst our people. 


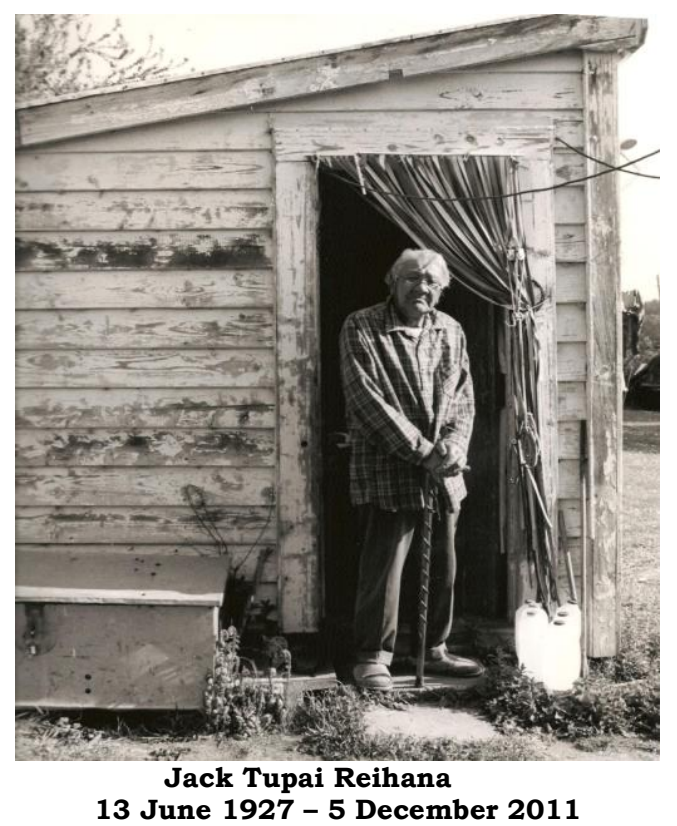

This Christmas just gone, on the 5th of December, an elder from Arowhenua marae in mid Canterbury, Jacko Reihana passed away. He was the last native speaker of our people to be raised in the South and in our dialect. As I arrived by myself at the door of the marae on the last night of the funeral and walked over to him and the family to pay my respects, our tradition dictates that the tears and laments flow freely, and they did. 

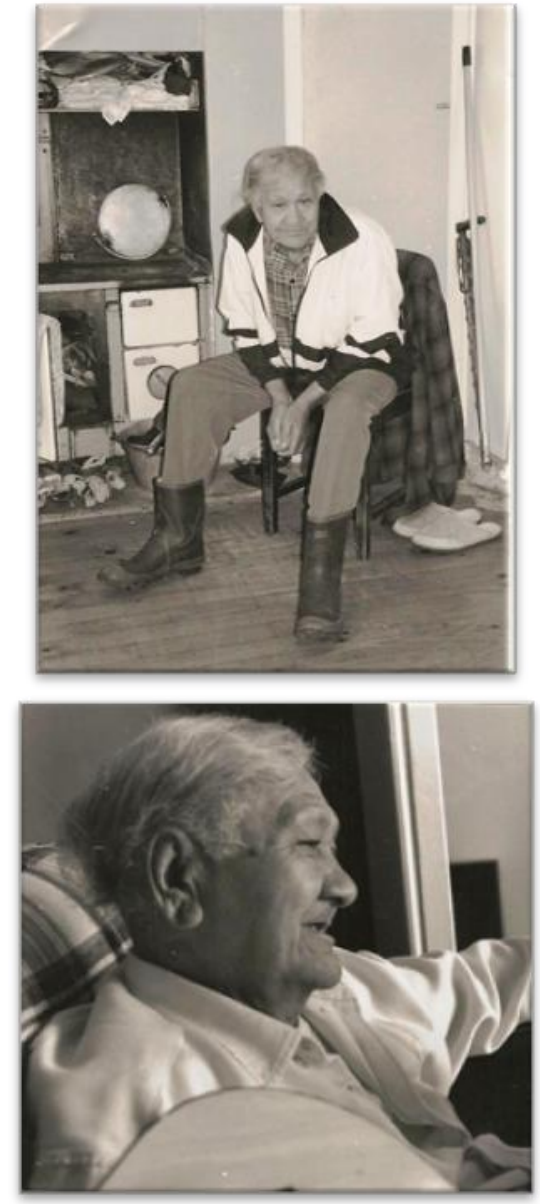

Te Kaharoa, vol. 5, Special Edition, 2012, ISSN 1178-6035 


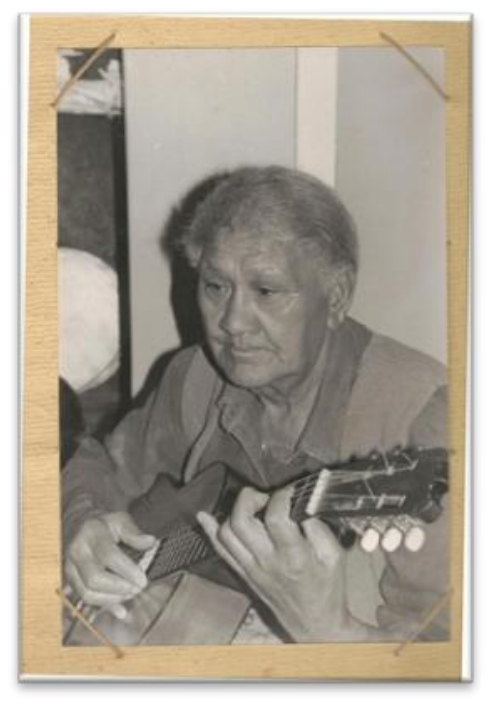

They flowed for the man he was, a gentle, larger than life man, with a soft voice and a great presence, not to mention a wicked hair style that he maintained until his passing. But they flowed also for what he represented, the world that he came from, and also what he took with him in his passing. And they flowed as I looked around to see a lonely pae - our bench of speakers and the empty seats in the big house. I cried for my tribe of 50,000 out of shame, that this man, the last speaker of our people could pass from our world with such little fanfare and so few to farewell him when one considered how many should have been there.

As we walked his body to the urupā or cemetery the next day, there were over a couple of hundred people, many his own grandchildren and great grandchildren, who joined in the procession, on his last journey. But there should have been thousands.

I believed that if our people truly understood what they had lost, if they truly valued and treasured our language and aspired to be again, a people who could speak their heritage language as a natural part of their being - they would have understood just what we lost that day with the death of Uncle Jacko.

So how do we, those of us who do know what we've got to loose and what has already been lost; and who desperately 
want to bring our fellow tribes-people on board - hope to compete with the ordinary pressures of everyday life, let alone the extraordinary pressures of life like natural disasters?

How do we succeed in turning the masses around so they too can appreciate the richness, and depth, the beauty and the cultural importance of our language and what we are at risk of losing forever from our grasp? What can we say or do to make others put in the hard work and make the commitment to learn, knowing full well that it will be hard, it will take a long time and they will have to make other sacrifices, and that there is no easy way to do it? How do we ignite the spark in their hearts? Is it indeed possible?

Perhaps it is no wonder that our world's languages are being lost at the fastest rate in the history of our humankind, when one considers the obstacles faced by the majority of the world's minority languages.

The accelerating extinction of languages on a global scale has no precedent in human history...Languages are far more threatened than birds $(11 \%$ threatened, endangered, or extinct), mammals (18\%), fish $(5 \%)$, or plants (8\%). (Harrison 2007:7)

Those of us already converted to the cause of indigenous language maintainence have likely already heard the predictions of leading linguists like that of K.D. Harrison, as articulated in his book "When languages Die - The extinction of the World's Languages and the Erosion of human Knowledge" (2007):

In the year 2001, at least 6912 distinct human languages were spoken worldwide. Many linguists now predict that by the end of our current $21^{\text {st }}$ century - the year 2101, only about half of these languages may still be spoken... At the current pace, we stand to lose a language about every 10 days for the foreseeable future (Harrison 2007:3 -5).

Even with this stark prediction, we seem deaf to the warnings. The current national reality In New Zealand is that $25 \%$ of the Māori population identify themselves as being able to speak te reo to some degree. Not all of that $25 \%$ are committed to speaking te reo in the homes and use it as the language of communication with their children. And that is before we start looking at the other $75 \%$. 
We have made significant progress in the last 25 years, but we are still to achieve a critical mass of speakers to ensure language survival into the next 100 years. As a minority language, we are still very much in the critical stage. We will not simply become one of the surviving 1000 languages (of the 6000 ) in a hundred years time - by chance. But by chance, and by apathy, we could certainly easily become one of the 5000 - and quickly so. That is the national situation, and as I've already highlighted, our tribal situation is much more severe.

Our small band of language advocates and workers have endeavoured to highlight the urgency of the language plight within our tribe and raise critical awareness for the past 12 years. We don't have the time here to go through a whole list of the strategies and initiatives employed, but all of them have been centred on language in the home, intergenerational transmission of the language and attempts to engage people on a language learning pathway no matter what their starting point is:

We developed family based language planning resources and employed community language planners to support individual families to bring the language in to the home environment. We wrote and developed a series of 4 texts and accompanying audio resources to build language in the home; We made and distributed over 1000 copies of games, puzzles, posters, modern Maori music CDs and Maori labels to put around the home.

We made and distributed a professional DVD to support the critical awareness around the state of the language alongside marketing campaigns promoting the language in our tribal media about raising bilingual children and then ran workshops around the South Island on raising bilingual children. We had Maori language holiday camps, fun family trips to exciting places in our territory along with community language classes and intensive language learning experiences for groups at different levels of language proficiency.

We composed and taught traditional songs, developed language resource websites with proficiency tests, and had. And we also had an initial Ngāi Tahu Māori language Awards in 2010 where we celebrated life-time commitments, community initiatives and champions and teachers of the language. The life time award went to composer and language supporter, Ruahine Crofts, who after receiving the award, at the end of the evening as she left the event, passed away. 
Despite these efforts - we have only managed to engage a comparatively small number of our 50,000 strong tribe. We would be lucky to have 1000 who are actively participating to some degree in language acquisition activities and even less, perhaps no more than 200, who are supporting language in the home. So, our wins have been few - very special and exciting wins, but not enough to give us any sense of ongoing security. We have also become alarmingly aware of the cultural deprivation that has gone alongside our language loss, and although this is a national issue for all Māori, it is acute within our tribal membership.

Unfortunately, the engagement side of the language revitalisation equation, only constitutes one part of the picture. So if I may now turn to the issue of language transformation I can highlight some of the challenges we have faced and continue to face on this journey:

\section{WHAKAKAU HE REO - Language transforming}

If we manage to succeed in igniting the spark in the hearts of more and more of our people to take up the challenge of language acquisition - we must also ensure that the language they are acquiring is of appropriate quality. With the language struggle within Māoridom, we have watched the kind of language spoken by language learners and speakers move through a range of phases and trends. In the early 1980s all emphasis was placed on achieving a critical mass and enticing people back into the language. We went far and wide, encouraging everyone to 'give it a go' and not hold back from speaking if they thought they were going to get it wrong.

The trend was to standardise the language to make it 'simpler' for the learner, so dialectal variance gave way to using a standard form of the language, that previously did not exist but was heavily influenced by two of the larger North Island tribes. Because of this process of standardisation or simplification, we started to see a limiting of those aspects language usually associated with dialect like proverbs and idiom. In fact it got to the point where you could almost guess in any Māori language class in the country, the key list of 20 proverbs that might be used - and it was as if idiom and the catchy, humorous sayings of our ancestors, were almost forgotten altogether.

This was the area that I started learning the language in and I worked hard to learn it. I achieved a level of proficiency 
that I was able to be quite proud of after formally learning te reo for 6 years. But even by the age of 21, when I found myself lecturing the language in one of our Southern Universities, I remained largely ignorant about the depth of our language form and the different genre appropriate to different domains. I loved humour, but had to work really hard to respond quickly and with wit to other people's comments. It was almost as if whole emotions were out of reach.

It wasn't until I went to one of Professor Karetu's week long intensive language workshops, that I was introduced to the world of kiwaha or idiom. I felt like a child being released into the most exciting linguistic playground I had ever seen. All of a sudden, I had access to phrases to express my emotions, pithy statements to summarise my point of view, or poignant words to capture the essence of my thoughts. My language transformed overnight from being one that was largely an awkward translation of English into Māori, to sounding more natural and realistic - to being Māori.

Although this epiphany was happening for me at a very personal level - the transformation started happening nationwide. By the mid 1990's the limitation of the simplified standardised approach was becoming more and more evident, as those who had taken up the challenge to learn started to teach their children and others' children and we started to hear children whose first language might have been Māori, but whose language quality was of significant concern, and who, as they grew older, would inevitably turn to English when they got mad or angry or needed to convey more complex messages.

The richness of the language that the various dialects brought with them, was soon to be recognised and valued again, and attempts were made to work on the depth and quality of te reo. This phase coincided with the time that our own tribal language revitalisation effort started to take shape, and we started to research and incorporate our own tribal sayings and dialectal characteristics into our teaching $\mathrm{My}$ own language proficiency continued to develop, although perhaps not as fast and successfully as my teachers would have liked. I had developed in a way that meant I could confidently give a lecture in the language on a range of topics, I could teach in a total immersion environment, participate in a public debate and write poetry and compose songs in the language. 
By the year 2000 our tribal language strategy was in its $3^{\text {rd }}$ year. I was already active alongside my peers attempting to sell the language goal to our people and excite them about the possibilities of language learning and raising their children with the language in the home.

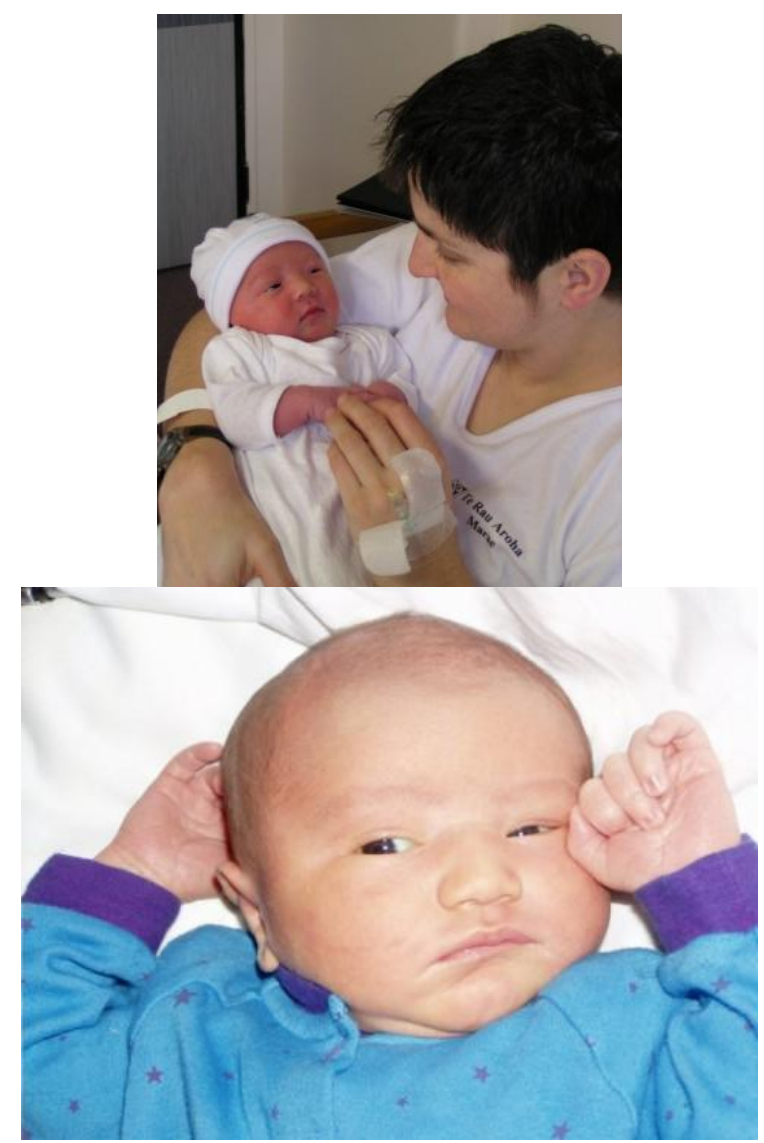

Hana with Manuhaea Rena 8 July 2003 Te Rautāwhiri Mahaki aged 3 days, 10 July 2004

I was humbled however, when I was fortunate enough to become a mother myself and held my own baby daughter in my arms. I was literally lost for words! I had never had 
intergenerational language modelled to me. All of a sudden my witty catch phases, deep and meaningful poetry and language debating skills, seemed somewhat redundant as I clumsily engaged in the new tasks of motherhood.

I hadn't had to know the word for "I'm going to tickle your stomach" or "let me lift up you legs so I can wipe you", in any of the language lectures I had given. And here I was - with my little baby girl, struggling for words on a daily, even hourly basis. Epiphany number two - was if it was that hard for me to do, as someone who had already attained a level of language - what did that mean for all of the 100s of parents I had been lecturing to about raising their children in te reo - who didn't have that level of language under their belts?

This experience of motherhood, which is a daily learning journey in itself, along with the other insights I had had on my own language learning path, intensified for me the need to consider the kind of language we were trying to revitalise and the specific strategies that might help aid those objectives.

I had learnt in a very short time, it wasn't good enough to simply learn the language and assume it would be able to be transferred across different language domains and transmitted across generations, and all the while maintain a sense of the traditional depth, breadth and quality of its traditional roots. But I did learn, that without deliberate planning in that regard, we could very easily loose what little precious time we had - as we struggled for its survival.

We couldn't run the risk of alienating the few people that we had managed to engage who had started learning the language - because we hadn't imparted the kind of language that would be relevant to them in their home life with their families, or that we had failed to transmit models of language which allowed them opportunities to fully and accurately express their range of emotions.

We know now, that our language is continuously transforming as it evolves and as we strive to keep it relevant, meaningful and 'used' in our modern tribal lives. We also know there is a lot of transformation that still needs to take place politically, socially and culturally if we wish our language within our people, to be one of the world's language survivors in our grandchildren's time.

But perhaps even more pertinent at this time, more than an acknowledgement of the transforming nature of language and all of the contributing factors that influence that transformation - is an acknowledgement that we need to 
transform. We, who have the responsibility to keep or revive our heritage languages, that they may be something that we can transmit to our future generations - we need to continuously exert all efforts to break the back of the apathy epidemic that consumes our people. We must create the necessary critical mass. No matter what obstacles we may encounter, be they earthquakes or the passing of our leaders and repositories of our language. It is our children's right to be whole.

I dedicate this presentation to Uncle Jacko, and to those still with us who likewise have dedicated their lives to the reo who have given so completely of themselves and taught a new generation the language of their hearts.

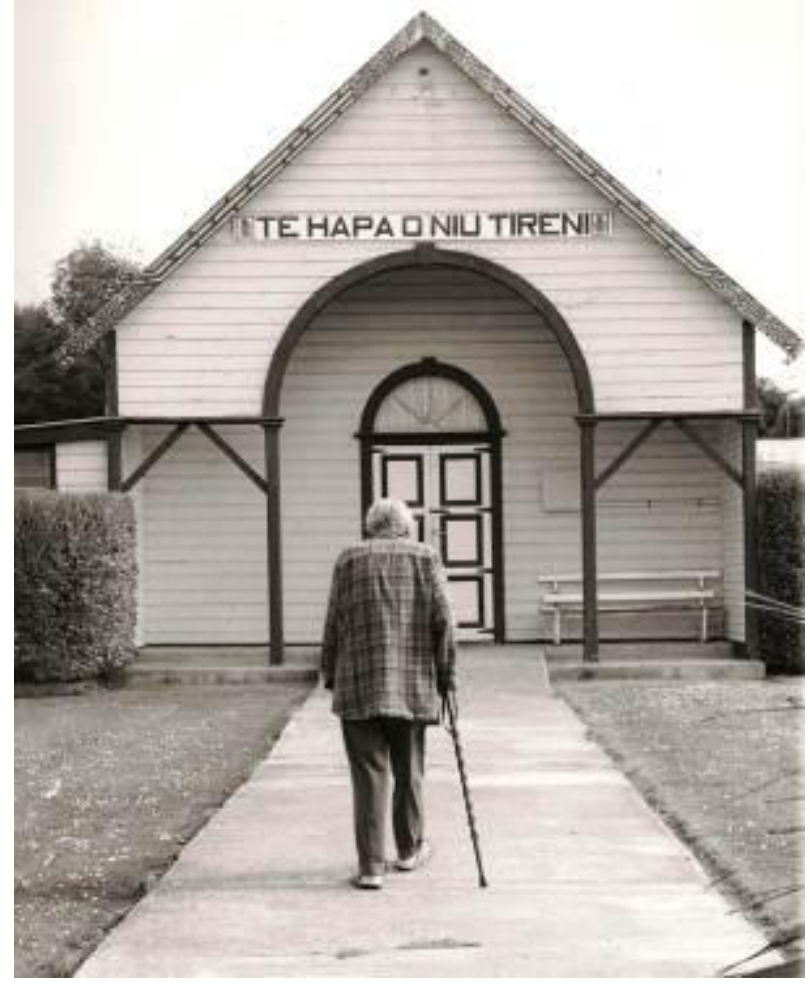

